\title{
Assessment of country-of-origin-related and -neutral elements of mobile communication service offers: An empirical study of consumers with a Turkish migration background in Germany
}

\author{
Torsten J. Gerpott* and Ilknur Bicak
}

Chair of Strategic Management, Focus Telecommunications Management, Mercator School of Management, University of Duisburg-Essen, Lotharstr. 65, D-47057 Duisburg, Germany

\begin{tabular}{l}
\hline C H R O N I C L E \\
\hline Article history: \\
Received January 28, 2015 \\
Received in revised format 6 \\
February 2015 \\
Accepted 7 February 2015 \\
Available online \\
February 102015 \\
\hline Keywords: \\
Consumers with migration \\
background \\
Ethno marketing \\
Limit conjoint-analysis \\
Mobile communication market \\
Offering attributes \\
Turkish immigrants in Germany
\end{tabular}

\section{Introduction}

In recent decades all over the world, a large number of people have left their countries of birth often due to economic reasons to live and work abroad. This trend will be further reinforced in the future (OECD, 2014). Against this background, management researchers and practitioners (Coskun 2011, pp. 29-50; Gerpott \& Bicak, 2011, pp. 100-102; Schneider et al., 2010, p. 165) pay increasing attention to the specific consumption patterns of individuals (1) who do not hold the citizenship of their country of residence (COR) or (2) who possess the COR nationality but were born abroad or have at least one

*Corresponding author. Tel: +49-203/379-3109, Fax +49-203/379-2656

E-mail addresses Torsten.Gerpott@uni-due.de (T. J. Gerpott) 
(grand)parent not originating from their current COR (= migrants or consumers with a migration background; Statistisches Bundesamt, 2014, pp. 5-6).

If companies deliberately address migrants with measures characterized by the ethnic and cultural identity of migrants, which diverge from those chosen for the native majority population this segmentspecific market cultivation is referred to as ethno marketing (Cinar, 2003, p. 24; Gerpott \& Bicak, 2011, p. 98; Kulinna, 2007, p. 9). Ethno marketing is based on the premises that (1) the ethnic and cultural identities of migrants and non-migrants differ significantly and (2) that these identity differences affect consumer responses to the use of marketing instruments and their consumption behavior.

The ethnic identity construct focuses on an individual's subjective sense of belonging to an ethnic group and the part of one's thinking, perceptions, feelings, and behavior, that is due to that ethnic group membership (Rotheram \& Phinney, 1987, p. 13). The degree of the ethnic imprint of a person's selfimage reflects the subjective life-relevancy of a person's belonging to an ethnic group whose members share the conviction to originate from the same social entity, which frequently settles in a certain territory. This group can be differentiated from other societies by cultural commonalities such as language, clothing, religion, music, food or other traditions (Cokley, 2007, p. 225; Hofstede, 2001, pp. 9-10; Yağmur \& Vijver, 2012, p. 1112-1113; Zick, 2010, p. 80). Thus, ethnic and cultural identifications are so inextricably intertwined that it is common practice in the literature to treat both identity facets as synonyms (Antioco et al., 2012, p. 381; Michaelis et al., 2008, p. 4; Ogden et al., 2004, p. 1; Zick, 2010, p. 418).

The ethnic identity of people does not necessarily result from their nationality because one state may be home to several ethnic groups (e.g., Turkey is home to Turks and to Kurds). Additionally, the objectively-identifiable citizenship is not necessarily a very strong determinant of the degree of an individual's subjective ethnic orientation (Wilamowitz-Moellendorff, 2001, pp. 16-17). Acknowledging potential intrapersonal divergences between ethnic and national identity, in the following marketing activities which focus on a migrant's country of origin (COO) are referred to as COO-related marketing rather than adhering to the popular but inaccurate term of ethno marketing.

Individuals whose direct or indirect COO is Turkey, by far, constitute the largest national group among migrants living in Germany (Statistisches Bundesamt, 2014, p. 56). They have a high purchasing power (Cinar, 2003, pp. 24-25; Coskun, 2011, p. 25). Consequently, it does not come as a surprise that COOrelated marketing measures for consumers with Turkish roots living in Germany (German-Turks) have gained some professional attention. However, the relevant literature is dominated by a high proportion of success stories by practitioners (Bücker, 2006; Cinar, 2003, Gehl, 2006; Hoffmann \& Demirel, 2011). In contrast, strong empirical studies on consumer attitudes, preferences, and behavior patterns of German-Turks are relatively scarce (positive exceptions are Anzengruber, 2008; Aygün, 2005; Coskun, 2011; Kulinna, 2007; Michaelis et al., 2008; Schneider et al., 2010). These few relevant investigations do not take into account that in practice Turkey-related offer elements are often interwoven with non-Turkey-related marketing components. For example, a printed car ad can be written in Turkish language, yet include a photograph of the vehicle that does not refer to Turkey but is generally used in marketing regardless of the national origin of potential buyers. Moreover, with the exception of Michaelis et al. (2008) earlier studies insufficiently consider that several COO-related marketing elements (e.g., price, brand, and advertising) may affect consumers, simultaneously. Given these research gaps, the key subject of the present paper is to explore the relative weight of various partly but not entirely COO-related offer features in the assessment of and preference formation for offers by German-Turkish customers.

Mobile communication service bundles are taken as an exeplary showcase to address the research topic. This service category was selected because COO-sensitive marketing activities for such services that go beyond mere foreign-language ad campaigns have already targeted German-Turkish consumers 
since 2005 (Hoffmann \& Demirel, 2011). Hence, in a field study it may be assumed that in this service category such a marketing approach is neither new nor unrealistic to the study participants.

In addition, the present study extends the state of knowledge on COO-related marketing for GermanTurks because, unlike many previous studies, it accounts for the possibility of increasing heterogeneity among consumers of Turkish origin in Germany (Dressler \& Köten, 2007, p. 32; Schneider et al., 2010, p. 174; Trebbe \& Weiß, 2007, p. 138). This is accomplished by exploring to what extent (a) subgroups within the segment of German-Turks can be identified which significantly differ in their preferences for different elements of mobile communication offers and (b) such subgroups deviate with respect to socio-demographic characteristics, mobile service consumption variables, and acculturation indicators.

These two substantive focal points do not only imply that the present work should help to extend scholarly knowledge regarding the assessment of COO-related offer components by German-Turks. Rather it should also support mobile service providers to derive useful hints on how to design marketing elements so that they better meet preferences of German-Turkish buyers. Additionally, it may contribute on how to realize an extended differentiation of customized services for various subgroups of German-Turks.

The remainder of this paper is structured as follows: Section 2 explains the elements of mobile communication products taken into consideration and develops the research questions. Subsequently, we present the data collection procedure and in particular the limit-conjoint analysis as the methodology chosen to address the research questions. Then, we report the empirical results. Section 5 concludes with a discussion of the implications of our results for management practice and future research.

\section{Design features of mobile communication offers and research questions}

The COO-related design of mobile communication offers in Germany is primarily achieved via pricing and promotion measures (Hoffmann \& Demirel, 2011). At the heart of price design are the charges for outgoing voice calls or text messages (SMS) from a mobile device to the target group's COO (in the present case Turkey). Regarding promotion policy design, particularly the use of the Turkish language in advertising and in customer care both before and after establishing a mobile communication customer business relationship are discussed (Bücker, 2006, pp. 99-100; Cinar, 2003, p. 28; Erdem \& Schmidt, 2008, p. 219). In addition, the option of developing a special brand identity tailored to consumers with Turkish roots, as it was first introduced in the German mobile communication industry by E-Plus with Ay Yildiz, has been highlighted (Bücker, 2006, p. 99; Michaelis et al., 2008, pp. 6-8). ${ }^{1}$ Finally, a less noticed COO-related promotional approach is the provision of funds for charitable projects in the target group's COO by donating a pre-determined and publicly announced share of the turnover realized with customers for the benefit of such projects (La Ferle \& Lee, 2005; Laufer et al., 2010; Singh et al., 2008). Positive effects of consumer preferences and behavior resulting from COOrelated promotional activities are mostly explained by recurring to arguments of the social identity theory of Tajfel et al. (1971) emphasizing the consumption impacts of perceptions of national or ethnic similarity between buyers and sellers which in turn are partially casused by their rootedness in the same COO.

The literature on consumption behaviors of German-Turks unanimously emphasizes the importance of price positioning of service offerings and distribution channels and COO-related communication activities for the buying behavior of this group (e.g., with respect to the food retailing industry Anzengruber, 2008, pp. 120-126, 288-291). However, it almost never comments on the relative

\footnotetext{
${ }^{1}$ The promotion instrument of creating a COO- or Turkey-oriented brand identity is not considered to be a separate offering feature in the following, as it strongly overlaps with the use of the Turkish language in advertising or in personal customer interactions.
} 
importance of various COO-related marketing elements for the formation of offer preferences. ${ }^{2}$ One positive exception is a study by Michaelis et al. (2008). In a sample of 90 young adults it analyzed the purchase intention for a mobile communication offer as a function of its COO-related price level (high vs. low) and the COO-adapted promotion activities (strong vs. weak) tailored to German-Turks. Michaelis et al. (2008, p. 12) found that the effect size of the promotion factor on purchase intention surpassed the effect size of the price factor by about a quarter, and that both factors significantly affected the offer preferences of the respondents.

All in all, the body of empirical evidence on the relative importance of COO-related pricing and promotion measures in shaping the evaluation of service offerings by migrants in general and of mobile communication services by German-Turks in particular qualifies as sparse.

In the German telecommunications market, as in many other countries, it is common practice that (new) customers are not solely offered the use of mobile services (Ishaq, 2011; Talberg et al., 2007). Rather network or service access is marketed in conjunction with an end-user device (usually a mobile phone). This device strongly influences the customer's experience in the actual network use and it thus significantly affects the assessment of the mobile service provider (Kim \& Yoon, 2004). Mobile phones are highly standardized technical systems that are produced for the world market in order to exploit economies of scale advantages by high volumes of production and sales. Manufacturers of such devices therefore typically strive to create a strong, globally uniform brand identity for the end-user equipment. The global reach of brands of mobile device manufacturers is reflected, among others, in the fact that these companies regularly occupy leading positions in rankings, which attempt to quantify the value of a company brand based on financial data or scoring procedures (Interbrand, 2012; SyncForce, 2013). Significant adjustments of the brands of mobile phone manufacturers to individual national markets do not take place. Consequently, the offer of a mobile access in conjunction with the sale of a telecommunication device characterized by a manufacturer's brand is to be classified as a non-COOrelated and therefore COO-neutral or culture-free offer/marketing element (for distinguishing between culture-free and culture-bound products cf. Coskun, 2011, pp. 137-139).

To the best of our knowledge, scholarly publications on preference effects of various mobile phone types or brands in conjunction with network access are missing both for mobile communication customers in Germany in general and for German-Turks in particular. Using the example of the device type or device brand this research compares preference effects of non-COO-related offer features to COO-sensitive marketing elements. The present study analyzes preference statements for purchase options which include a mobile service access only bundled with a mobile device. The characteristics of the offer attribute mobile phone were varied so that devices of manufacturers diverging in their brand strength had to be assessed. Quantifications of the brand value of global corporations in 2011 (Interbrand, 2011; SyncForce, 2011) and sales statistics for mobile phones in Germany in 2011 (GfK 2011) suggested that at the time of the data collection mobile phones marked as iPhone 4 by Apple ( $N 900$ from Nokia) were representing a device with a very strong brand (with moderate brand strength). However, a mobile phone that is marked as a no name device which can be purchased at a lower price than the iPhone 4 and Nokia N900, may be characterized as an offer attribute without a strong brand identity. Consequently, in our preference survey the attribute mobile phone was considered with the three levels Apple iPhone 4, Nokia N900, and no name.

The variation of the brand strength of the offer element mobile device was included because several publications stress that, often globally oriented, strong brands without a COO-relation may have a high purchase relevance to German-Turks which significantly surpasses the corresponding influence weight detected for the native majority in Germany (Allgayer, 2010, p. 72; Anzengruber, 2008, pp. 276-287;

\footnotetext{
2 The terms offer-related preference, assessment and utility are used interchangeably here to refer to subjective attractivity evaluations of objects for which consumers have to make a purchase decision.
} 
Batato, 2005, p. 92; Cinar, 2003, p. 25 and p. 29; Zollinger, 2005, p. 62; for a different view see Kulinna, 2007, pp. 203-205). The large impact of brands on the purchase decision is generally explained as an attempt of German-Turks to compensate for their lack of social status (Bücker ,2006, p. 101 [translated]) up to the present day by possessing/consuming branded products. Especially the brand of mobile communication devices may generate a supplementary benefit which goes far beyond the technical-functional core utility of the product. The device itself or rather its brand creates an additional brand-based self-expression value signalling the buyer's financial capacities and personal lifestyle to other persons in his or her personal surroundings (see Gutsche et al., 2005, pp. 640-641; Petruzzellis, 2010, pp. 615-624).

No previous studies are available which compare the effects of COO-neutral offer elements such as the type or brand of a mobile phone and COO-sensitive pricing and promotional offer attributes on German-Turks' preferences; neither for the mobile communications market nor for any other offering categories.

Given the knowledge gaps outlined above, the following research questions (RQ) are addressed with our study:

$\mathrm{RQ}_{1}$ : What are the relative weights of the COO-independent attribute type/brand of a mobile device and of the three COO-sensitive attributes price for voice calls to Turkish fixedlines, price for sending SMS into Turkish mobile networks, and Turkey-specific customer communication in affecting the assessment of mobile communication offers by GermanTurks?

$\mathrm{RQ}_{2}$ : How do the levels of the four attributes referred to in $\mathrm{RQ}_{1}$ influence the assessment of mobile offers by German-Turks?

These questions imply that within the group of German-Turks individual preferences are very similar with regard to the design of mobile offerings. Yet, many studies on living conditions and consumer behaviors of German-Turks posit that this homogeneity premise for migrants of Turkish origin is not valid (Schneider et al., 2010, p. 174 [translated]; Dressler \& Köten, 2007, p. 32). Hence, it is presumed that German-Turks differ in their consumption behaviors or can be divided according to their consumption patterns, respectively into distinct subsegments or generations mainly as a function of their age, length of stay in Germany, their formal educational level and the strength with which they orient their self-image towards the basic values of the Turkish and German national cultures (Anzengruber, 2008, pp. 48-51 and pp. 338-346; Aygün, 2005, pp. 155-199; Coskun, 2011, p. 47; Geschke et al., 2011, p. 432; Holtz \& Wagner, 2011, p. 517; Trebbe \& Weiß, 2007, pp. 137-138). Especially for mobile services, the existence of such microcultures (Ogden et al., 2004, p. 1) and the diversity of its members with respect to socio-demographic characteristics and variables reflecting the consumption of mobile services and the degree of adaptation to the culture of the native majority in Germany, i.e., their acculturation (cf. for many Coskun, 2011, p. 78; Zick, 2010, pp. 33-94 and pp. 409520) has not yet been explored in scholarly studies.

Therefore, our study strives to contribute towards answering the following additional research questions:

RQ3: To what extent is it possible to identify distinct segments of German-Turks who differ in their preferences regarding the design of mobile communication offers?

RQ4: How do subgroups of German-Turks with deviating preferences for mobile communication offer designs differ in objective socio-demographic characteristics and variables which capture facets of their mobile communication consumption behaviors and in indicators of their degree of Germany-related acculturation? 


\section{Empirical methodology}

\subsection{Survey design and sample description}

A written, standardized questionnaire with mostly closed response formats was used to collect the data. The survey instrument was formulated at first in German, translated into Turkish, and was then backtranslated by two German-Turk bilinguals (Richard \& Toffoli, 2009, pp. 989-992). This procedure enabled us to provide subjects with the alternative to participate either in German or Turkish language. Before the field use of the instrument, eight Turkish native speakers pretested it with respect to comprehensibility, clarity, and relevance of the questions and response options. The final optimized questionnaire was publicly accessible online via an Internet link. Various online portals and communities solicited participation in our survey (e.g., www.alaturka.info). In parallel, a paper version of the questionnaire was distributed to persons with a Turkish migration background attending seminars held by the researchers and these individuals were requested to return the completed instrument. The personally contacted consumers were also asked to invite their Turkish relatives and friends to partake in the study by passing the printed questionnaire or the URL of the electronic instrument (for a similar snowball approach see Watchravesringkan, 2011). The offline channel was used to reach consumers with a low Internet affinity. Only subjects who reported that at least their mother or father was born in Turkey and that they were above the age of 15 at the time the survey was conducted were eligible to fill in the electronic version or the hard copy of the research tool.

In total, 135 German-Turks finished the online survey and 173 persons with a Turkish origin completed the paper questionnaire. ${ }^{3}$ The respondent groups did not differ significantly $(p>0.05)$ in terms of their distributions of six socio-demographic characteristics (nationality, gender, age, marital status, educational level, and household net income). Therefore, the respondents of both groups are combined hereafter.

Of the 308 participants, 249 (= 80.4\%) completely filled in the question block placed in the last quarter of the survey instrument which contained the (conjoint) stimuli to capture preferences with regard to the research-relevant attributes of mobile communication offers. Therefore, these persons form the sample analyzed in the remainder of the paper.

Table 1 reports the distribution of the participants' answers to six socio-demographic questions (see variables 1-6 in Table 1) and to three queries which deal with their mobile communication consumption behaviors (see variables 7-9 in Table 1). Our sample does not differ significantly from the total population of at least 16 year-old German-Turks in terms of the distribution of the socio-demographic characteristic of gender ( $\mathrm{p}>0.82)$ according to the Federal Statistical Office (Statistisches Bundesamt 2014). However, compared to this population, the sample includes too many single, 16- to 35 year-old (thus, young) persons with a German university entrance qualification (Abitur) and German citizenship and a monthly household net income of less than 1,000 EUR (Statistisches Bundesamt, 2014).

The distributions of the three variables characterizing the mobile communication consumption behavior of respondents in the sample cannot be compared to those in the overall population due to a lack of relevant official statistics. In qualitative terms, however, it can be stated that in our sample postpaid customers with monthly mobile communication expenditures of at least 35 EUR, i.e., people with high

\footnotetext{
${ }^{3} 350$ printed questionnaires were distributed, so that the response rate in the offline recruitment channel amounted to $49.4 \%$. A comparison of the socio-demographic characteristics between offline participants and non-participants is not possible, since for the latter there is no data present. A comparison of the study subjects who completed the questionnaire in the first month of the survey period, with those who did in the last month of the survey period, in terms of six socio-demographic variables (citizenship, gender, age, marital status, graduation, and household net income) showed that they were not significantly different ( $p>0.05$ ) distributed in both groups. According to Armstrong \& Overton (1977) this can be taken as an indication that no strong non-response bias exists.
} 
use of mobile communication services, are overrepresented relative to the overall mobile market in Germany (Bundesnetzagentur, 2014, pp. 76).

\section{Table 1}

Sample characteristics

\begin{tabular}{|c|c|c|c|c|c|}
\hline \multirow{2}{*}{$\begin{array}{l}\text { Socio-demographic } \\
\text { characteristics }\end{array}$} & \multicolumn{2}{|c|}{ Frequency } & \multirow{2}{*}{$\begin{array}{l}\text { Mobile service use behavior- } \\
\text { related characteristics }\end{array}$} & \multicolumn{2}{|c|}{ Frequency } \\
\hline & Absolute & (\%) & & Absolute & (\%) \\
\hline Citizenship $(\mathrm{n}=226)^{a}$ & & & Contract type $(\mathrm{n}=231)$ & & \\
\hline German $[=1]^{b}$ & 137 & $(60.6 \%)$ & Postpaid [= 1] & 185 & $(80.1 \%)$ \\
\hline Turkish $[=0]$ & 89 & $(39.4 \%)$ & Prepaid $[=0]$ & 46 & $(19.9 \%)$ \\
\hline Gender $(n=228)$ & & & Mobile tariff type $(\mathrm{n}=231)$ & & \\
\hline Male $[=1]$ & 117 & $(51.3 \%)$ & Special Turkey-Tariff [= 1] & 54 & $(23.4 \%)$ \\
\hline Female $[=0]$ & 111 & $(48.7 \%)$ & Without Turkey-Tariff $[=0]$ & 177 & $(76.6 \%)$ \\
\hline Age $(n=230)$ & & & Monthly expenses for mobile s & $=231)$ & \\
\hline $16-35$ years & 126 & (54.8\%) & Less than 25 EUR $[=1]$ & 71 & $(30.7 \%)$ \\
\hline $36-45$ years & 70 & $(30.4 \%)$ & $25-55$ EUR $[=1]$ & 126 & $(54.5 \%)$ \\
\hline $46-66$ years & 34 & $(14.8 \%)$ & At least 55 EUR [= 0] & 34 & $(14.8 \%)$ \\
\hline Marital status $(n=229)$ & & & Household net income $(\mathrm{n}=205$ & & \\
\hline Single $[=1]$ & 98 & $(42.8 \%)$ & Less than 500 EUR $[=1]$ & 23 & $(11.2 \%)$ \\
\hline Married [= 0$]$ & 111 & $(48.5 \%)$ & $500-999$ EUR [= 1] & 10 & $(4.9 \%)$ \\
\hline Divorced/Widowed [= 0] & 20 & $(8.7 \%)$ & At least 1,000 EUR $[=0]$ & 172 & $(83.9 \%)$ \\
\hline \multicolumn{6}{|l|}{ Graduation $(\mathrm{n}=216)$} \\
\hline University entrance diploma $[=1]^{c}$ & 128 & $(59.3 \%)$ & & & \\
\hline No university entrance diploma $[=0]$ & 88 & $(40.7 \%)$ & & & \\
\hline
\end{tabular}

a) $n=$ Number of respondents, who filled in the conjoint part of the questionnaire completely and additionally answered the respective question.

b) Figure in squared brackets = Coding of variable levels in the group comparisons displayed in Tables 4 and 5 .

c) Includes university entrance diplomas obtained in Turkey.

All in all, in socio-demographic terms our sample is not representative for the total adult population of Turkish origin in Germany. Yet, with regard to socio-demographic and mobile communication consumption variables it has sufficient variance to examine how subgroups with diverging preferences for the design of mobile communication services differ in respect to these variables. It also contains a considerable share of German-Turks with an above-average mobile use intensity. This target group is of particular interest for mobile communication service providers who are considering to differentiate themselves from their competitors by COO-related offer elements.

\subsection{Conjoint analysis for measuring preferences for mobile communication offer features}

In consumer surveys quantitative preference data for different offer attributes can be obtained by quite a number of methods. Most commonly they are differentiated in compositional and non-compositional approaches (Sattler, 2006, p. 156). In compositional methods consumers directly evaluate single offer attributes. In contrast, in decompositional approaches various offer attribute levels are assessed holistically. From these judgments conclusions regarding the attractiveness or the utilities a consumer attaches to offer attributes/levels are derived by statistical algorithms. In our study, preferences were estimated by traditional conjoint analysis (CA). This decompositional method was chosen because compared to direct assessments of single offer attributes it has validity advantages (Sattler, 2006, p. 170). In a traditional CA (potential) consumers are asked to assess several multiattributive offers (= conjoints, stimuli), each entailing different combinations of the attributes under study according to their subjective attractiveness or purchase probability on rating or rank order scales. ${ }^{4}$ This analysis method can be divided into ideal-typical steps (Backhaus et al., 2011, pp. 462-479), whose implementation in our investigation is described subsequently.

\footnotetext{
${ }^{4}$ Cf. the pioneering research of Green \& Rao (1971). Besides the traditional CA, choice-based CA (CBCA) and hierarchical CA (HCA) are frequently used in management research. However, CBCA and HCA compared to the traditional CA have not been proven to be clearly better preference measurement methods (Sattler, 2006, pp. 169-170). Consequently, the recourse to traditional CA to investigate preferences of German-Turks for different mobile communication offer designs is methodologically tenable.
} 
In the first step, the attributes and their respective levels were selected which were supposed to be essential for German-Turks in the assessment of partly COO-sensitively adapted mobile communication offers and thus influence their purchase decisions. The choice of the four attributes sketched in section 2 was based on approaches to a COO-related orientation of retail mobile communication offerings observed in the German telecommunications market (Bertele, 2010; Hoffmann \& Demirel, 2011), a review of the Anglosaxon ethno marketing literature (Gerpott \& Bicak, 2011), and on industry-specific work that discusses the design of mobile communication services from a customer perspective (e.g., Gutsche et al., 2005).

Appropriate attribute levels for the variables price for voice calls to Turkish fixed-lines and for sending a text message into Turkish mobile networks were identified by analyzing the respective prices as they were set by the four mobile network operators (MNO) active in Germany for these offer elements immediately prior to the data collection. The review showed that for a mobile call to Turkish fixedlines (SMS sent into Turkish mobile networks) the average market price was 0.23 EUR per minute (0.31 EUR per SMS). Therefore, these values were used as medium level for the attribute price per call minute and SMS unit price in the CA. Based on this, the low or high levels for these two characteristics were determined by varying the reference values of 0.23 EUR and 0.31 EUR each by 0.02 EUR upwards and downwards. Other price elements (e.g., activation fee) and complex multi-part tariff models (Schlereth \& Skiera, 2012, pp. 167-168) were discounted to keep the complexity of CA design at an acceptable level.

For the attribute COO-related promotion the three levels Turkish-language advertising, Turkishspeaking customer care, and a donation of 0.04 EUR per voice call and per SMS to support social projects in Turkey were used. The first two attribute levels were selected on the one hand due to the unanimous emphasis placed in the general literature on the language of COO-sensitive offers (Dressler \& Köten, 2007, p. 25; Makgosa, 2012, p. 374). On the other hand, they were considered to take into account industry-specifically that during the purchase and often in the subsequent use phase of mobile communication services face to face or medially mediated interactions between consumers and representatives of the mobile service company take place, whose process outcome can be significantly affected by whether or not the interactions are conducted in Turkish or German. The third attribute level was introduced in order to consider also a promotion measure which is a less common practice in Germany. The presented absolute amount of donations of 0.04 EUR for each voice connection or SMS corresponds to the range between the upper and lower limits of the investigated Turkey-related prices for mobile voice calls and SMS per unit (see above).

For the fourth offer attribute mobile device type/brand, the three levels (Apple iPhone 4, Nokia N900, no name-device) have already been explained in section 2 as an avenue to include a COO-neutral offer attribute with levels characterized by clearly differentiable brand strengths. To stress the aspect of brand strength even more effectively, the three attribute levels were anchored not only by mentioning the respective device, but also by providing the information on their respective purchase price. The prices were set for the Apple iPhone 4 at 650 EUR, for the Nokia N900 at 500 EUR, and for the no-name unit at 50 EUR. These prices were equal to to the mean price for the devices raised by $\mathrm{MNO} /$ services providers and mobile device manufacturers in Germany as of March 2011, in case the equipment was purchased by consumers without closing a mobile service contract, which entailed a specific minimum revenue for the contract seller.

Secondly, given that 81 alternatives resulted from the attributes and attribute levels selected in step 1, an incomplete orthogonal fractional survey design with 9 conjoints was chosen. The stimuli were selected in a way that allowed for the interpolation of an utility function for each attribute combination not directly included in the survey (Backhaus et al., 2011, pp. 466-467). 
In the third step, the nine conjoints composed of one level for each of the four attributes were presented to the participants. They were asked to bring them in a rank-order according to their attractiveness ranging from 1 = best liked of all 9 offers to $9=$ least liked of all 9 offers. The possibility to assign the same rank to various stimuli was precluded. Subsequently, the respondents were instructed to state up to which rank the mobile communication offer alternatives appeared sufficiently attractive to be bought. The option to nominate all or none of the alternatives/variants was explicitly mentioned. This limitquestion/-card (Voeth \& Hahn, 1998, p. 121) allows to infer the zero point of an individuals' utility function for the offer variants captured. Below this point, German-Turks would not buy the alternatives since they perceive a change for the worse compared to their current mobile consumption situation. Assuming equidistance between the rankings a total utility value for each stimulus was calculated according to Voeth \& Hahn (1998, p. 121) by deducting the rank assigned to a mobile offer alternative from the limit rank and by adding a constant of 0.5 to this difference.

In the last step the preference scores of the 9 stimuli - calculated as described above - were estimated using the CA-procedure contained in the SPSS22.0 package. It uses ordinary least-squares regressions to estimate part-worth utilities (PU) from the attribute levels for each individual respondent. The procedure assumes an additive-compensatory function of the attributes and a weighting function which does not require a specific steady type of association between the attribute levels and their utilities, but treats the level of an attribute as nominally scaled (Backhaus et al., 2011, pp. 469-471 and pp. 485-486; Voeth \& Hahn, 1998, p. 123). The resulting PU reflect the non-standardized effect of an attribute level on stated mobile offer design preferences expressed in the rank-order of the nine variants. Then, standardized PU (SPU) are derived from the non-standardized PU in a way that the sum of the maxima (minima) of the PU values equals 1 (0) for each participant (Backhaus et al., 2011, pp. 476-477 and footnote $b$ in Table 2). The SPU statistic eases comparisons of stated mobile offer preferences across participants because it controls for mean mobile offer stimuli assessment differentials between subjects.

\subsection{Measurement of remaining study variables}

$R Q_{4}$ referred to socio-demographic characteristics and variables referring to the facets of an individual's mobile communication consumer behavior. As in previous studies, these variables were captured each by a direct question with closed response options (Anzengruber, 2008, pp. 400-401; Aygün, 2005, p. 230; Coskun, 2011, pp. 210-214). The options can be found in Table 1.

The strength of the imprinting of ethnic identity of migrants by cultural elements of the native majority in their COR, i.e., the degree of acculturation, can either be captured by attitudinal constructs (e.g., the index of acculturation by Ryder et al. 2000, p. 65) or by more objectively observable behavioral indicators which are supposed to reflect the importance of cultural aspects of the COR for the ethnic identity of migrants (Gerpott \& Bicak 2012, pp. 66-67; Ogden et al. 2004, p. 5). In the present study, eight behavior-related variables (see appendix) were extracted from earlier work (Aygün, 2005, pp. 3940 and pp. 155-157; Callister et al., 2007, p. 34; Eastlick \& Lotz, 2000, p. 153; Esser, 2006, pp. $224-$ 228, 305-320 and pp. 471-472; Kang, 2006, pp. 676-688; Polat, 2006, pp. 170-172; Trebbe \& Weiß, 2007, pp. 136-138) and taken as indicators of the Germany-related acculturation of the surveyed consumers with Turkish roots.

The present paper refrains from measuring acculturation solely based on intrapersonal feelings as the usefulness of this approach for a target group-oriented design of mobile communication offerings in practice is very limited due to the lack of knowledge concerning the level of subjective acculturation attitudes of German-Turkish mobile consumers. In contrast, it is advantageous to operationalize acculturation by behavior-related features of a person since facets of the acculturation status of consumers with a migration background are easier to observe for mobile service providers. Additionally, these features can be used as a basis to generate offer variants, if preferences of persons differ as a function of their level of acculturation. We refrained from integrating the eight acculturation 
indicators into one (formative) index of acculturation (Schneider et al., 2010, p. 170 [translated]) in order to gain a multi-layered picture of indicator differences for German-Turks with different preferences. Such a picture facilitates practitioners to determine consumer characteristics, suitable to define segments in a simple manner, which are to be acquired or bound with different variants of mobile communication offers.

\section{Empirical results}

\subsection{Offer preferences in the total sample}

The limit CA findings relevant for answering the first two research questions are reported in Table 2. It shows mean, median, and standard deviation statistics of the unstandardized and standardized PU for the total 12 attribute levels of the 4 design features covered. In addition, it presents for each attribute level the proportion of participants who have a positive unstandardized PU. For example, the level donation of 0.04 EUR per call/SMS for charitable projects in Turkey of the attribute Turkey-related promotion had a positive preference effect for $68.3 \%$ of the subjects; in contrast, the level Turkish language advertising of the same attribute contributes positively to the evaluation of just 20.5\% (see no. 3.3 and 3.1 in Table 2).

\section{Table 2}

CA results for preferences of German-Turkish consumers concerning mobile communication offerings

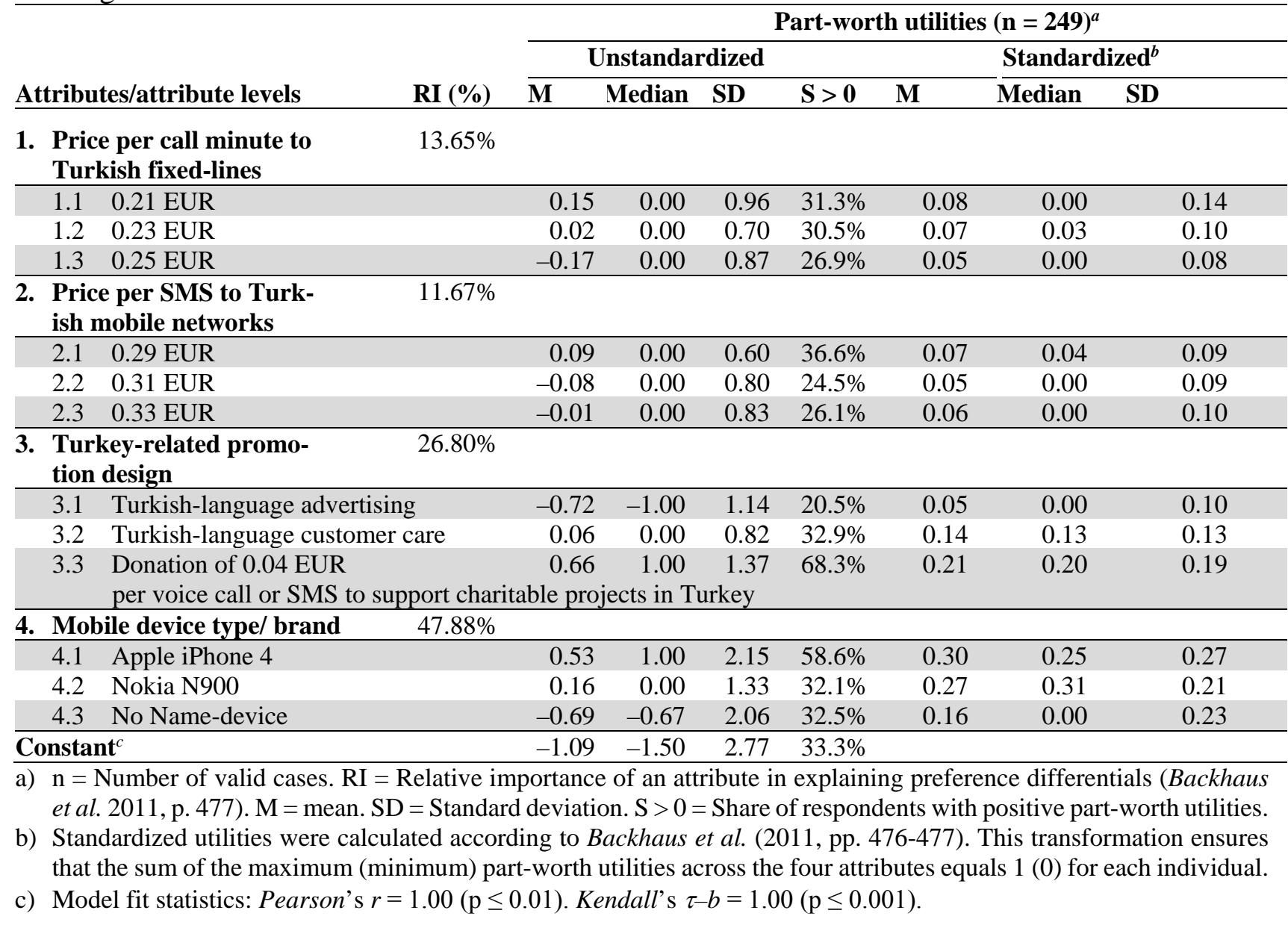

The negative average constant utility of -1.09 of the unstandardized preference model in Table 2 indicates that the basic utility of all offer variants captured was negative in the total sample compared to the actual consumption situation. Based on the unstandardized PU of the attributes included in the CA, for the average German-Turkish consumer a positive utility value resulted only from six of the 81 possible alternatives. The typical German-Turkish consumer in the sample would accept only those 
offers that include the Apple iPhone 4 for 650 EUR and a donation of 0.04 EUR per call/SMS to social projects in Turkey, because other- wise a change for the better compared to the offer currently used is not perceived.

The (internal) validity of the estimated preference models can be evaluated by using the mean average of the Pearson- or Kendall-correlations between the observed and the model-based predicted ranks of the 9 conjoints for the 249 German-Turks (Backhaus et al., 2011, pp. 485-486). Both correlation averages amounted to 1.0 (see Table 2, footnote c). This suggests that the estimated individual utility functions are able to reproduce the ranks stated by the subjects in the questionnaire. Thus, the predictive validity of the limit CA is satisfactory.

With regard to research question $\mathrm{RQ}_{1}$, which addressed relative contributions of the four attributes to the stated preferences of German-Turkish mobile communications users, Table 2 shows that the mobile device type/brand as a non-COO-related offer component had the strongest influence on the participants' preferences with a weight of $47.88 \%$. The attribute Turkey-related promotion achieved a weight of $26.80 \%$ and therefore turned out to have a weaker effect by more than 20 percentage points. The relative preference effects of the two COO-related price aspects amounted to $13.65 \%$ and $11.67 \%$ (attributes 1 and 2 in Table 2), and correspond in sum to about the amount of the relative weight that is observed for the COO-related promotion for the 249 German-Turks. Overall, with respect to $\mathrm{RQ}_{1}$ it can be concluded that the COO-insensitive offer aspect (concretely the end-user device) influenced preferences for mobile communication offers in the sample almost as strongly as three COO-related attributes together.

Concerning research question $\mathrm{RQ}_{2}$ the results in Table 2 reveal, as expected, that for the two price attributes the lowest levels provide the most positive utility contributions. The level Turkish-language advertising of the attribute Turkey-related promotion exhibits a preference-reducing effect compared to the other two levels. This result means that in the sample the customer care in the COO-language or the financial support of charitable projects in Turkey by the own use of mobile service is experienced more positive than Turkish-language advertising messages (see for the negative effect of COO-related advertising activities among migrants also Michaelis et al., 2008, pp. 15-16). The PU averages of the attribute levels for mobile device type/brand suggest a strong brand consciousness among GermanTurks in assessing the value of the mobile equipment, as two-thirds of respondents preferred the two branded devices over the no name-device despite its lower price.

\subsection{Subsegments of German-Turks with diverging preferences with regard to the design of mobile communication offerings}

Research question $\mathrm{RQ}_{3}$ concerns the degree of homogeneity of Turkish mobile customers' preferences regarding the design of MNO offerings. The standard deviations of the PU values of the 12 attribute levels in Table 2 turn out high compared to their respective mean values. This may be taken to suggest that the study participants can be partitioned into several subsegments with different preferences regarding the mobile offering design. The soundness of this assumption was explored by subjecting the individual SPU of the 12 attribute levels were to a hierarchical agglomerative cluster analysis in order to obtain an ex-post segmentation of the 249 respondents. In the cluster analysis, also computed with SPSS22.0, the squared Euclidean distance was used to capture preference similarities between various subjects. Ward's minimum variance method was selected as the algorithm to identify clusters with SPU being as homogeneous in itself as possible (cf. Backhaus et al., 2011, pp. 426-430). The elbow criterion that looks at changes in the sum of squared errors as a function of the number of groups differentiated and inspections of SPSS-dendrograms unanimously suggested that the present data set contained four clusters with diverging preferences regarding the configuration of mobile communication offers. Table 3 displays SPU means and standard deviations as well as the unstandardized PU means for the 12 attribute levels in the CA for each of the four preference clusters. Table 3 additionally reports the results 
of one-way factorial analyses of variance (ANOVA) of the SPU values in the four subsegments. According to the ANOVA, the SPU values for 11 of 12 attribute levels in the four clusters differed at a significance level of at least $0.1 \%$. The detected clusters are briefly described below.

Table 3

Comparison of standardized part-worth utilities of mobile communication offer attributes across the four clusters

\begin{tabular}{|c|c|c|c|c|c|c|c|c|c|c|}
\hline \multirow{3}{*}{$\begin{array}{l}\text { Attribute/ } \\
\text { attribute levels }\end{array}$} & \multicolumn{8}{|c|}{ Descriptive part-worth utilities statistics $^{a}$} & \multirow{2}{*}{\multicolumn{2}{|c|}{$\begin{array}{l}\text { Test for mean } \\
\text { differences } \\
\text { (ANOVA) }\end{array}$}} \\
\hline & \multicolumn{2}{|l|}{$\begin{array}{l}\text { Cluster } 1 \\
(\mathbf{n}=\mathbf{4 0}) \\
\text { "Socially } \\
\text { minded" }\end{array}$} & \multicolumn{2}{|c|}{$\begin{array}{l}\text { Cluster } \mathbf{2} \\
\text { (n= 66) } \\
\text { "Strongly brand } \\
\text { affiliated" }\end{array}$} & \multicolumn{2}{|c|}{$\begin{array}{l}\text { Cluster } 3 \\
(\mathbf{n}=\mathbf{7 6}) \\
\text { "Use-price } \\
\text { sensitive" } \\
\end{array}$} & \multicolumn{2}{|c|}{$\begin{array}{l}\text { Cluster } 5 \\
(\mathbf{n}=\mathbf{6 7}) \\
\text { "iPhone averse" }\end{array}$} & & \\
\hline & $\overline{\mathbf{M}}$ & SD & $\overline{\mathbf{M}}$ & SD & $\mathbf{M}$ & SD & $\overline{\mathbf{M}}$ & SD & $F$-value ${ }^{b}$ & $\mathbf{p} \leq$ \\
\hline \multicolumn{11}{|c|}{ 1.Price per call minute to Turkish fixed-line } \\
\hline $1.1 \quad 0.21 \mathrm{EUR}$ & $\begin{array}{c}0.07 \mathrm{w} \\
{[0.19]} \\
\end{array}$ & 0.11 & $\begin{array}{r}0.05_{\mathrm{w}} \\
{[0.10]}\end{array}$ & 0.09 & $\begin{array}{r}0.18_{\mathrm{x}} \\
{[0.51]}\end{array}$ & 0.19 & $\begin{array}{r}0.02_{\mathrm{w}} \\
{[-0.22]} \\
\end{array}$ & 0.05 & 25.22 & 0.000 \\
\hline $1.2 \quad 0.23$ EUR & $\begin{array}{r}0.04_{w} \\
{[-0.20]}\end{array}$ & 0.05 & $\begin{array}{r}0.03_{W} \\
{[-0.06]}\end{array}$ & 0.05 & $\begin{array}{r}0.14 \mathrm{x} \\
{[0.14]}\end{array}$ & 0.12 & $\begin{array}{r}0.04_{\mathrm{w}} \\
{[0.08]}\end{array}$ & 0.07 & 27.51 & 0.000 \\
\hline 1.30 .25 EUR & $\begin{array}{c}0.06 \\
{[0.01]}\end{array}$ & 0.07 & $\begin{array}{c}0.03 \\
{[-0.04]}\end{array}$ & 0.05 & $\begin{array}{c}0.07 \\
{[-0.65]} \\
\end{array}$ & 0.11 & $\begin{array}{c}0.05 \\
{[0.14]}\end{array}$ & 0.07 & 2.27 & 0.081 \\
\hline \multicolumn{11}{|c|}{ 2.Price per SMS to Turkish mobile networks } \\
\hline $2.10 .29 \mathrm{EUR}$ & $\begin{array}{r}0.07_{\mathrm{w}} \\
{[0.22]} \\
\end{array}$ & 0.06 & $\begin{array}{r}0.03_{\mathrm{w}} \\
{[0.10]} \\
\end{array}$ & 0.05 & $\begin{array}{r}0.12_{x} \\
{[0.10]}\end{array}$ & 0.11 & $\begin{array}{r}0.05_{W} \\
{[0.01]} \\
\end{array}$ & 0.08 & 13.39 & 0.000 \\
\hline $2.2 \quad 0.31$ EUR & $\begin{array}{r}0.03_{\mathrm{w}} \\
{[-0.14]} \\
\end{array}$ & 0.06 & $\begin{array}{r}0.02_{W} \\
{[-0.05]} \\
\end{array}$ & 0.03 & $\begin{array}{r}0.12_{x} \\
{[0.22]} \\
\end{array}$ & 0.12 & $\begin{array}{r}0.02_{\mathrm{w}} \\
{[-0.42]} \\
\end{array}$ & 0.03 & 35.57 & 0.000 \\
\hline $2.3 \quad 0.33$ EUR & $\begin{array}{l}0.04_{\mathrm{w}, \mathrm{x}} \\
{[-0.08]} \\
\end{array}$ & 0.06 & $\begin{array}{r}0.02_{\mathrm{W}} \\
{[-0.05]} \\
\end{array}$ & 0.03 & $\begin{array}{r}0.07 x \\
-0.32] \\
\end{array}$ & 0.11 & $\begin{array}{r}0.09_{\mathrm{x}} \\
0.41] \\
\end{array}$ & 0.13 & 8.67 & 0.000 \\
\hline \multicolumn{11}{|c|}{ 3.Turkey-related promotion design } \\
\hline $\begin{array}{l}.1 \text { Turkish-language } \\
\text { advertising }\end{array}$ & $\begin{array}{r}0.01_{\mathrm{W}} \\
{[-2.51]} \\
\end{array}$ & 0.02 & $\begin{array}{r}0.03_{\mathrm{w}} \\
{[-0.65]} \\
\end{array}$ & 0.06 & $\begin{array}{r}0.12_{x} \\
{[0.01]}\end{array}$ & 0.14 & $\begin{array}{r}0.04_{\mathrm{w}} \\
{[-0.52]} \\
\end{array}$ & 0.06 & 18.68 & 0.000 \\
\hline $\begin{array}{ll}3.2 \text { Turkish-language } \\
\text { customer care }\end{array}$ & $\begin{array}{r}0.26_{W} \\
{[-0.16]} \\
\end{array}$ & 0.15 & $\begin{array}{r}0.11_{x} \\
{[0.03]} \\
\end{array}$ & 0.07 & $\begin{array}{r}0.12_{x} \\
{[0.06]}\end{array}$ & 0.17 & $\begin{array}{r}0.12_{\mathrm{x}} \\
{[0.21]} \\
\end{array}$ & 0.06 & 16.49 & 0.000 \\
\hline $\begin{array}{ll}3.3 & \text { Donation for } \\
& \text { Turkey }^{c}\end{array}$ & $\begin{array}{r}0.56_{w} \\
{[2.67]}\end{array}$ & 0.13 & $\begin{array}{r}0.18_{x} \\
{[0.62]}\end{array}$ & 0.11 & $\begin{array}{r}0.11_{y} \\
{[-0.07]}\end{array}$ & 0.11 & $\begin{array}{l}0.15_{\mathrm{x}, \mathrm{y}} \\
{[0.31]}\end{array}$ & 0.11 & 157.29 & 0.000 \\
\hline \multicolumn{11}{|l|}{ 4. Mobile device/brand } \\
\hline 4.1 Apple iPhone 4 & $\begin{array}{r}0.17 w \\
{[0.46]}\end{array}$ & 0.12 & $\begin{array}{r}0.68_{x} \\
{[2.82]} \\
\end{array}$ & 0.10 & $\begin{array}{r}0.24_{n} \\
{[0.98]}\end{array}$ & 0.17 & $\begin{array}{r}0.08_{y} \\
{[-2.20]} \\
\end{array}$ & 0.15 & 236.39 & 0.000 \\
\hline 4.2 Nokia N900 & $\begin{array}{r}0.13_{w} \\
{[0.09]}\end{array}$ & 0.10 & $\begin{array}{r}0.36 \mathrm{x} \\
{[0.16]}\end{array}$ & 0.03 & $\begin{array}{r}0.06 y \\
{[-0.92]}\end{array}$ & 0.09 & $\begin{array}{r}0.48_{z} \\
{[1.41]}\end{array}$ & 0.19 & 182.08 & 0.000 \\
\hline 4.3 No Name-device & $\begin{array}{l}0.06_{\mathrm{w}, \mathrm{x}} \\
{[-0.56]}\end{array}$ & 0.10 & $\begin{array}{r}0.00_{\mathrm{w}} \\
{[-2.99]}\end{array}$ & 0.00 & $\begin{array}{r}0.14_{x} \\
{[-0.06]}\end{array}$ & 0.17 & $\begin{array}{r}0.40_{y} \\
{[0.79]}\end{array}$ & 0.27 & 66.83 & 0.000 \\
\hline
\end{tabular}

a) Standardized part-worth means with varying subscripts (w, $\mathrm{x}, \mathrm{y})$ differ significantly after a Bonferroni-adjustment at $\mathrm{p}$ $\leq 0.05$ (two-tailed) in a pairwise F-test. Figures in squared brackets = mean of unstandardized part-worth utilities. The mean unstandardized part-worth utility constant across the nine stimuli was $-1.91(\mathrm{SD}=2.41)$ in cluster $1,-1.21(\mathrm{SD}=$ $2.13)$ in cluster $2,-1.51(\mathrm{SD}=3.17)$ in cluster 3 und $0.01(\mathrm{SD}=2.79)$ in cluster 4.

b) $\mathrm{df}=3,244$.

c) Donation of 0.04 EUR per voice call or SMS to support charitable projects in Turkey.

The 40 respondents in cluster 1 (16.1\% of the total sample) primarily distinguish themselves from the remaining subjects by particularly preferring mobile communication offers which include a donation to charitable projects in Turkey. Therefore, we label members of this cluster 1 as socially minded (SM).

The 66 individuals in cluster 2 (26.5\% of all participants) evaluate mobile communication offers aboveaverage positive (negative) if they include a mobile device with a strong brand (without a brand identity). In contrast, their preferences are affected weakly by COO-related prices for voice calls and SMS. Therefore, the members of the second cluster are specified as strongly brand affiliated (SBA). 
Cluster 3 contains 76 German-Turks (30.5\% of the sample) and differs significantly with regard to the mean PU values in four (five) of the six levels of both COO-sensitive price attributes at least at the 5\% level from each (two) of the remaining three other segments (see Table 3). Due to these differences, we characterize respondents of cluster 3 as use-price sensitive (UPS).

The remaining 67 participants in cluster 4 (26.9\% of the respondents) mostly deviate from members of the other groups in terms of their mobile device: Members of this cluster assign a lowest PU value to the attribute level Apple iPhone 4, which significantly undercuts the corresponding mean in each of the other three groups. Conversely, the mean PU values of the other two device levels (Nokia N900, no name-device) in cluster 4 exceed the corresponding means of the other three preference clusters. Against this background, consumers in cluster 4 are denoted iPhone averse (iPA).

To sum, it may be stated with regard to research question RQ3 that in the present sample of 249 GermanTurks four subsegments (three of which are of a similar size) can be identified which significantly differ with respect to their preferences for the design of COO-related and neutral attributes of mobile communication offers. Thus, our study suggests that the conclusion that German-Turks are not a homogeneous consumer group - which was already highlighted in research for other product categories - also holds up for mobile communication offers.

4.3 Comparison of preference clusters in terms of socio-demographic characteristics, mobile communication-behavioral variables and acculturation indicators

To address research question $\mathrm{RQ}_{4}$ the four clusters characterized by heterogeneous offer preferences are compared with respect to five socio-demographic and three variables capturing aspects of mobile service use behavior (see Table 4). A multivariate analysis of variance (MANOVA), in which the eight variables were entered simultaneously as dependent variables explained by the cluster membership, resulted in a Wilks' $\lambda$ of 0.78 which is significant at the $0.1 \%$ level. This means that the four segments are somehow different (Hair et al., 2006, p. 413) with respect to the eight dependent variables. To illuminate these differences, one-factorial ANOVA for the five socio-demographic variables and three variables related to mobile service use behavior were carried out. The ANOVA results are also presented in Table 4.

According to the results, the four clusters diverge in terms of age and monthly mobile phone expenses of its members at a significance level of $0.1 \%$ and $2.7 \%$, respectively. iPA individuals, averaging 39.2 years, are significantly older than the strongly brand affiliated German- Turks of cluster 2 (mean: 31.5 years). The age difference between the iPA and the members of cluster 1 (SM) and 3 (UPS) misses the commonly accepted significance threshold of $10 \%$ with values of $12 \%$ and $14 \%$ not very clearly. Regarding monthly mobile expenditures the UPS differ from the SBA in pairwise comparisons by a significantly lower proportion of cases, which does not spend more than 55 EUR per month for mobile services.

All in all, the examined five socio-demographic and the three mobile communication-related variables contribute to the explanation of the observed preference differences in our Turkish-German sample only to a rather limited extent. The subsegments of the SBA and the iPA are most likely to be differentiated from each other in socio-demographic terms based on the characteristics age and gender (SBA: rather young and male; iPA: rather middle-aged and female).

Analogous to the procedure for the socio-demographic and mobile communication behavior-related respondent characteristics, the eight behavior-related acculturation indicators were ini-tially compared simultaneously in a MANOVA to test the set of variables for their overall differences across the four preference clusters. With a Wilks' $\lambda$ of 0.61 highly significant at the $0.1 \%$ level the MANOVA indicates that there are considerable differences in the distributions of the acculturation indicators across the four preference clusters. 


\section{Table 4}

Comparisons of socio-demographic and mobile service consumption behavior-related variables across the four clusters

\begin{tabular}{|c|c|c|c|c|c|c|c|}
\hline \multirow{3}{*}{\multicolumn{2}{|c|}{ Variables }} & \multicolumn{4}{|c|}{ Distribution statistics $^{\mathbf{a}}$} & \multirow{2}{*}{\multicolumn{2}{|c|}{$\begin{array}{l}\text { Test for distribu- } \\
\text { tion differences }\end{array}$}} \\
\hline & & \multirow{3}{*}{$\begin{array}{l}\text { Cluster } 1 \\
\text { "SM" }\end{array}$} & \multirow{3}{*}{$\begin{array}{l}\text { Cluster } 2 \\
\text { "SBA" }\end{array}$} & \multirow{3}{*}{$\begin{array}{l}\text { Cluster } 3 \\
\text { "UPS" }\end{array}$} & \multirow{2}{*}{$\begin{array}{l}\text { Cluster } 4 \\
\text { "iPA" }\end{array}$} & & \\
\hline & & & & & & $\overline{\chi^{2}-/ F \text {-value }}{ }^{\mathrm{b}}$ & $\mathrm{p} \leq$ \\
\hline I. & Socio-demographic charact & & & & & & \\
\hline \multirow[t]{2}{*}{1.} & Gender: Share male & $40.5 \%$ & $59.0 \%_{w}$ & $41.8 \%$ & $39.7 \% \%_{x}$ & 7.64 & 0.054 \\
\hline & & [37] & [61] & {$[67]$} & [63] & [228] & \\
\hline \multirow[t]{2}{*}{2.} & Average age in year & 34.2 & $31.5_{w}$ & 35.7 & $39.2_{\mathrm{x}}$ & 5.98 & 0.001 \\
\hline & & [37] & {$[62]$} & {$[68]$} & {$[63]$} & [230] & \\
\hline \multirow[t]{2}{*}{3.} & Marital status: Share & $43.2 \%$ & $46.8 \%$ & $49.3 \%$ & $31.7 \%$ & 4.69 & 0.198 \\
\hline & Single & {$[37]$} & {$[62]$} & [67] & [63] & [229] & \\
\hline \multirow[t]{2}{*}{4.} & Household net income: & $83.6 \%$ & $80.6 \%$ & $65.7 \%$ & $74.6 \%$ & 7.58 & 0.269 \\
\hline & Share $\geq 1,000$ EUR & [37] & [62] & {$[67]$} & [63] & [229] & \\
\hline \multirow[t]{2}{*}{5.} & Education level: Share & $58.3 \%$ & $53.7 \%$ & $60.0 \%$ & $63.9 \%$ & 1.27 & 0.740 \\
\hline & $\begin{array}{l}\text { with university entrance } \\
\text { diploma }\end{array}$ & [36] & [54] & [65] & [61] & [216] & \\
\hline \multicolumn{8}{|c|}{ II. Mobile communication behavior-related characteristics } \\
\hline & Contract type: Share & $78.4 \%$ & $87.5 \%$ & $75.8 \%$ & $78.1 \%$ & 3.20 & 0.365 \\
\hline & postpaid & [37] & [64] & [66] & [64] & [231] & \\
\hline \multirow[t]{2}{*}{7.} & Mobile tariff type: Share & $18.9 \%$ & $17.2 \%$ & $21.2 \%$ & $34.4 \%$ & 6.27 & 0.099 \\
\hline & with special tariff for Turkey & [37] & [64] & {$[66]$} & [64] & [231] & \\
\hline & Monthly expenses for & $91.9 \%$ & $93.8 \%_{w}$ & $77.3 \% \%_{x}$ & $81.3 \%$ & 9.15 & 0.027 \\
\hline & $\begin{array}{l}\text { mobile services: Share } \\
\text { up to } 55 \text { EUR }\end{array}$ & [37] & [64] & {$[66]$} & [64] & [231] & \\
\hline
\end{tabular}

a) SM = Socially minded. SBA = Strongly brand affiliated. UPS = Use-price sensitive. iPA = iPhone averse. Figures in squared brackets $=$ Number of respondents with valid answers included in the analysis. Percentage values or means with varying subscripts $(\mathrm{w}, \mathrm{x})$ differ significantly after a Bonferroni-adjustment at $\mathrm{p} \leq 0.05$ (two-tailed) in a pairwise $\chi^{2}$-or F-Test, respectively.

b) $\mathrm{df}=3$. Except for variable $2 \chi^{2}$-values are displayed. For variable 2 the $F$-value of an ANOVA is shown.

As can be seen from Table 5 the subsegment of the iPA diverges significantly from of the remaining three groups. iPA were rarely born or naturalized in Germany. They live in neighbor-hoods with a high share of people with a Turkish origin. They classify their German language skills often not as good or very good, thus consequently a large share of them did not fill in the German version of our questionnaire. Taken as a whole, iPA German-Turks in our sample are characterized by a lower degree of Germany-related acculturation or social integration (cf. Trebbe \& Weiß, 2007, p. 136), although, on average they already live in Germany about as long as the members of the other three preference clusters. In comparisons of the distributions of acculturation indicators between the cluster pairs SM vs. SBA, SM vs. UPS, and SBA vs. UPS no significant differences were found. Accordingly, for these three preference clusters their degree of acculturation is likely to be similar.

\section{Implications}

\subsection{Managerial conclusions}

COO-sensitive marketing approaches for German-Turks are discussed for more than one decade in the management literature and have been practically implemented for specific offer categories by quite a number of companies. Such approaches are based on the assumption that customers with a Turkish origin in Germany are more inclined to choose providers that address them with reference to their ethnic and cultural roots differently from the German majority population. To date, the tenability of this premise has been scarcely analyzed in empirical studies. Moreover, the few existing studies have focused on exchange goods, which implies that contract goods, which entail a long term relationship with a service provider (Kaas 1995, pp. 23-24), remain unconsidered (Anzengruber, 2008; Aygün, 2005; Coskun, 2011; Schneider et al., 2010).

The present study, in which preferences of 249 German-Turks for four attributes of mobile services (i.e., services in a market that can largely be characterized as contract business (Rams, 2001, pp. 131132)) were explored, provides evidence that the above-mentioned assumption requires a nuanced consideration. 
Table 5

Comparisons of acculturation indicators across the four preference clusters

\begin{tabular}{|c|c|c|c|c|c|c|}
\hline \multirow{3}{*}{$\begin{array}{l}\text { Acculturation } \\
\text { indicators }\end{array}$} & \multicolumn{4}{|c|}{ Distribution statistics $^{\mathbf{a}}$} & \multirow{2}{*}{\multicolumn{2}{|c|}{$\begin{array}{c}\text { Test for distribu- } \\
\text { tion differences } \\
\text { (ANOVA) }\end{array}$}} \\
\hline & \multirow{2}{*}{$\begin{array}{l}\text { Cluster } 1 \\
\text { "SM" }\end{array}$} & \multirow{2}{*}{$\begin{array}{l}\text { Cluster } 2 \\
\text { "SBA" }\end{array}$} & \multirow{2}{*}{$\begin{array}{l}\text { Cluster } 3 \\
\text { "UPS" }\end{array}$} & \multirow{2}{*}{$\begin{array}{l}\text { Cluster } 4 \\
\text { "iPA" }\end{array}$} & & \\
\hline & & & & & $\overline{\chi^{2}-/ F \text {-value }}{ }^{\mathrm{b}}$ & $\mathrm{p} \leq$ \\
\hline \multirow{2}{*}{$\begin{array}{l}\text { 1. Country of birth: } \\
\text { Share Germany }\end{array}$} & $43.2 \%$ & $59.7 \%_{w}$ & $48.5 \%$ & $28.6 \% \%_{x}$ & 12.64 & 0.005 \\
\hline & {$[37]$} & {$[62]$} & [68] & [63] & & \\
\hline \multirow{2}{*}{$\begin{array}{l}\text { 2. Citizenship: Share } \\
\text { German }\end{array}$} & $78.4 \%_{w}$ & $64.5 \%$ & $62.7 \% \%_{w}$ & $41.9 \%$ & 19.75 & 0.003 \\
\hline & [37] & {$[62]$} & {$[67]$} & {$[62]$} & & \\
\hline \multirow{2}{*}{$\begin{array}{l}\text { 3. Spouse's country of } \\
\text { birth: Share Germany }\end{array}$} & $18.2 \%$ & $17.6 \%$ & $12.5 \%$ & $2.8 \%$ & 8.66 & 0.193 \\
\hline & {$[22]$} & [34] & [32] & [36] & & \\
\hline \multirow{2}{*}{$\begin{array}{l}\text { 4. Spouse’s citizenship: } \\
\text { Share Germany }\end{array}$} & $68.2 \%$ & $61.8 \%$ & $59.4 \%_{w}$ & $38.9 \% \%_{x}$ & 17.10 & 0.047 \\
\hline & [22] & [34] & [32] & [36] & & \\
\hline \multirow{2}{*}{$\begin{array}{l}\text { 5. Length of stay in } \\
\text { Germany (years) }\end{array}$} & 29.8 & 26.2 & 27.6 & 25.4 & 2.41 & 0.067 \\
\hline & [37] & {$[62]$} & [67] & [63] & & \\
\hline \multirow{2}{*}{$\begin{array}{l}\text { 6. Share of Turks in } \\
\text { the neighborhood: } \\
\text { Share high/very high }\end{array}$} & $42.5 \%$ & $43.9 \%$ & $25.0 \% \%_{\mathrm{w}}$ & $56.7 \%_{x}$ & 15.10 & 0.002 \\
\hline & {$[17]$} & [29] & [19] & {$[38]$} & & \\
\hline \multirow{2}{*}{$\begin{array}{l}\text { 7. German language } \\
\text { skills: Share good/ } \\
\text { very good } \\
\end{array}$} & $87.5 \% \%_{w}$ & $80.3 \%_{w}$ & $82.9 \% \%_{w}$ & $56.7 \% x$ & 19.16 & 0.000 \\
\hline & [35] & [53] & [63] & [38] & & \\
\hline \multirow{2}{*}{$\begin{array}{l}\text { 8. Language of question- } \\
\text { naire: Share German }\end{array}$} & $80.0 \% \%_{w}$ & $78.8 \% \%_{w}$ & $67.1 \%$ & $53.7 \%$ & 12.56 & 0.006 \\
\hline & {$[40]$} & {$[66]$} & [76] & [67] & & \\
\hline \multicolumn{7}{|c|}{$\begin{array}{l}\text { a) SM = Socially minded. SBA = Strongly brand affiliated. UPS = Use-price sensitive. iPA = iPhone averse. For variable } \\
5 \text { the mean instead of a percentage share is reported. The standard deviation of this variable in the SM-cluster is } 6.86 \\
\text { in the SBA-cluster } 8.79 \text {, in the UPS-cluster } 7.47 \text { and in the iPA-cluster } 10.29 \text {. Percentage values or means with varying } \\
\text { subscripts (w, x) differ significantly after a Bonferroni-adjustment at } \mathrm{p} \leq 0.05 \text { (two-tailed) in a pairwise } \chi^{2} \text {-test. Figures } \\
\text { in squared brackets = Number of respondents with valid answers. }\end{array}$} \\
\hline
\end{tabular}

At least in the mobile communication market, our findings indicate that non-COO-related offer elements (end-user device type/brand), which appear appropriate to signal the social status and the lifestyle of a consumer visible for others to see, by far, outweigh the explicitly COO-sensitively designed offer features in the preference formation. COO-related offer attributes are not automatically irrelevant, but they may only serve as hygiene factors that make an offer to be shortlisted, but in the end - unlike the brand strength of a device as part of the service bundle in mobile telecommunication - are not pivotal for the purchase.

Moreover, our findings suggest to treat German-Turks not as one homogeneous segment (any longer) (similarly Coskun, 2011, p. 191). Instead, in mobile communications this target group comprises four subsegments in our sample, which differ significantly in their preferences regarding the captured four/twelve attributes/attribute levels. For mobile service operators, this heterogeneity implies that a systematic differentiation in offers may be advantageous for subgroups of German-Turks, provided that no additional costs arise. If our results are generalizable for German-Turkish mobile communication users, then mobile service providers should offer besides one variant, which targets younger male customers by highlighting mobile phones with a strong brand identity such as the Apple iPhone 4, at least two more offer types. One variation could be the linking of telephone calls/number of SMS of German-Turkish customers with the financial support of charitable projects in Turkey. A second option may be generated by including the purchase of a mobile phone, which can be positioned as a credible alternative to the lifestyle emphasizing Apple brand. With the latter variation, according to our results young, female German-Turks exhibiting a below-average Germany-related degree of acculturation could be addressed. 
Finally, our results have the implication for mobile service providers that attractive COO-related price elements do not necessarily have to be the focus of promotion campaigns directed at German-Turks. Price levels of voice calls/SMS to Turkey have below-average preference effects in the target group as compared to other offer features (for similar conclusions unrelated to specific offer categories see Akyol ,2002; Gehl, 2006)

\subsection{Study limitations and suggestions for future research}

Just like any empirical investigation the present study also has limitations, from which suggestions for further research can be derived. In our opinion, five worthwhile avenues for future work deserve special attention.

First, preferences for mobile communications services in response to only four attributes with three attribute levels each were examined. This restriction was chosen in order to avoid a cognitive overload of the study participants with a (too) complex CA design. It is obvious that additional attributes possibly relevant for preferences (e.g., contract duration, change-of-tariff flexibility, prices for voice calls/SMS within Germany) and the levels of the attributes considered (e.g., device brands from Asian manufacturers) were ignored. Future work could therefore include other attributes.

Second, it seems likely that the relatively average high utility ascribed to the attribute level of a predefined amount per voice call/SMS discharged for charitable projects in Turkey (see, item 3.3 in Table 2) may be due to a tendency that the respondents have answered in a socially desirable manner, which permits only limited inferences with regard to their true preferences and purchase patterns. Counter to this thesis one may argue that according to analyses by Hofstede (2001, p. 215 and p. 500), the Turkish national culture compared to Germany is characterized by a strongly collectivist orientation that is reflected in donations to people who come from the same COO as the donor. To clarify the tenability of these divergent lines of reasoning (field-)experimental studies are ultimately necessary. They could explore particularly actual demand behaviors of German-Turks for mobile communication offers which include a donation component resembling to that in our work and, thus, find out to what extent CAbased stated preferences converge with revealed preferences in everyday consumption.

Third, we have analyzed the offer assessments as a function of attributes for just one service category with contractual good features, for which the inclusion of COO-related aspects in the offer (price) design is easy to accomplish. Therefore, the transferability of our findings regarding the preference heterogeneity of German-Turks for mobile communication service packages to other offer categories, in which COO-sensitive offer differentiation is more difficult to realize (such as home appliances, life insurance), should be tested in additional studies.

Fourth, we observed in our study significant preference differences of German-Turks depending on their Germany-related degree of acculturation. This raises the questions of why especially among the members in cluster 4 (iPhone averse), containing $27 \%$ of the sample, the degree of acculturation was significantly lower, albeit between the preference clusters no significant differences in length of stay in Germany exist. For addressing these issues, longitudinal studies would be appropriate which analyze acculturation processes and their interactions with consumption behaviors mainly with qualitative research methods, (see for instance as a relevant example Üstüner \& Holt, 2007).

Fifth, our work focused on Turkish consumers in Germany. A large number of people from other countries of origin also live in Germany (especially Russia, Poland; see Statistisches Bundesamt, 2014, pp. 6 and 82). Consequently, studies are desirable which analyze to what extent observations made for German Turks (high preference heterogeneity and high preference effect of strong mobile device brands in mobile communication offers) may also hold up for migrant groups in Germany which are rooted in countries other than Turkey. 
All in all, given our findings, we suggest two fundamental conclusions in light of the identified open research issues, and the fact that Germany is likely to remain a country of immigration in the future (see, OECD, 2014, pp. 20-27 and 256-257). First, business practitioners should note that effective COO-sensitive marketing (ethno marketing) for migrants at least in the mobile communications business appears difficult without further differentiation of consumers with the same COO. Second, for scholarly business research it should be acknowledged that the optimal alignment of COO-sensitive and COO-neutral offering elements is a topic area in which considerable knowledge increments are possible and necessary.

\section{References}

Akyol, K. (2002). Lebenswelt Deutschtürken. Direkt Marketing, 38(8) 24-26.

Allgayer, F. (2010). Vielfalt türkischer Lebenswelten. Werben und Verkaufen, 48(50), 72-73.

Antioco, M., Vanhamme, J., Hardy, A., Bernardin, L. (2012). On the importance of social integration for minority targeting effectiveness, International Journal of Research in Marketing, 29, 380-389.

Anzengruber, M. (2008). Sozial orientiertes Konsumentenverhalten im Lebensmittelhandel. Wiesbaden: Gabler.

Armstrong, S., Overton, T. (1977). Estimating nonresponse bias in mail surveys. Journal of Marketing Research, 14, 396-402.

Aygün, T. (2005). Deutschtürkisches Konsumentenverhalten. Köln: Eul.

Backhaus, K., Erichson, B., Plinke, W., \& Weiber, R. (2011). Multivariate Analysemethoden, $13^{\text {th }}$ ed. Berlin: Springer.

Batato, F. (2005). Türken sind für Markenartikler die besseren Kunden. Absatzwirtschaft, 48(12), 92.

Bertele, C. (2010). Ethno-Anbieter: Die Heimat am Hörer. Telecom Handel, available at: http://www.telecom-handel.de/Marktreports/Mobilfunk/Ethno-Anbieter-Die-Heimat-am-Hoerer (accessed 27 January 2015).

Bücker, M. (2006). Potenzial für Ethno-Marketing wird kräftig unterschätzt. Absatzwirtschaft, 49(12), 96-101.

Callister, P., Didham, R., Newell, J., \& Potter, D. (2007). Family ethnicity: Knitting a jumper using two woolly concepts. Social Policy Journal of New Zealand, 15(32), 32-48.

Cinar, M. (2003). Ethnospezifisches Marketing für Deutschtürken: Probleme und Chancen. Thexis, 20 (4), 24-29.

Cokley, K. (2007). Critical issues in the measurement of ethnic and racial identity. Journal of Counseling Psychology, 54, 224-234.

Coskun, B. (2011). Interaction of Cultural and Socio-Economic Variables in Targeting Ethnic Consumer Groups. Berlin: Steinbeis Edition.

Dressler, M., \& Köten, N. (2007). Werbeeffektivität von Ethnowerbung am Beispiel der Türken in Deutschland. Werbeforschung und Praxis, 52(2), 24-35.

Eastlick, M.A., \& Lotz, S.L. (2000). Objective and multidimensional acculturation measures: Implications for retailing to Hispanic customers. Journal of Retailing and Consumer Services, 7, 149-160.

Erdem, K., \& Schmidt, R. (2008). Ethnic marketing for Turks in Germany. International Journal of Retail and Distribution Management, 36, 212-223.

Esser, H. (2006). Sprache und Integration. Frankfurt/Main: Campus.

Gehl, C. (2006). Konsumverhalten der Deutsch-Türken. Media \& Marketing, (12), 24-26.

Gerpott, T.J., \& Bicak, I. (2011). Ethno-Marketing: Synopse empirischer Studien sowie Schlussfolgerungen für die Marketing-Praxis und -Forschung. Der Markt, 50, 97-108.

Gerpott, T.J., \& Bicak, I. (2012). Ethnische Identitäten von Migranten. Wirtschaftswissenschaftliches Studium, 41, 64-70.

Geschke, D., Möllering, A., Schmidt, D., Schiefer, D., \& Frindte, W. (2011). Meinungen, Einstellungen und Bewertungen: Die standardisierte Telefonbefragung von Nichtmuslimen und 
Muslimen. In Frindte,W., Boehnke, H., Kreikenbom, H., Wagner, W. (Eds.), Lebenswelten junger Muslime, Bundesministerium des Innern, Berlin, pp 106-433, available at:

http://www.bmi.bund.de/SharedDocs/Downloads/DE/Broschueren/2012/junge_muslim e.pdf?_blob=publicationFile (accessed 27 January 2015).

GfK (2011). Apple iPhone schlägt Nokia bei Marktanteil in Deutschland. Nürnberg: GfK.

Gutsche, J., Herrmann, A., Huber, F., Kressmann, F., \& Algesheimer, R. (2005). Die Wirkung funktionaler, emotionaler und relationaler Nutzendimensionen auf die Markenloyalität. ZfbF Schmalenbachs Zeitschrift für betriebswirtschaftliche Forschung, 57, 638-657.

Hair, J., Black, W.C., Babin, B.J., Anderson, R.E., \& Tatham, R.L. (2006). Multivariate Data Analysis, $6^{\text {th }}$ ed. Upper Saddle River: Pearson.

Hoffmann, S., \& Demirel, F. (2011). Ethno-Marketing im deutschen Mobilfunkmarkt: Entdeckung neuer Zielgruppensegmente. Planung und Analyse, 38(5), 52-55.

Hofstede, G. (2001). Culture's Consequences, $2^{\text {nd }}$ ed. Thousand Oaks: Sage.

Holtz, P., \& Wagner, W. (2011). Muslimische Lebenswelten im Kontext: Muslimische Internetforen und Fokusgruppen mit jungen Muslimen. In Frindte, W., Boehnke, H., Kreikenbom, H., Wagner, W. (Eds.), Lebenswelten junger Muslime, Bundesministerium des Innern, Berlin, 434-517, available at: http://www.bmi.bund.de/SharedDocs/Downloads/

DE/Broschueren/2012/junge_muslime.pdf?_blob=publicationFile (accessed 27 January 2015).

Interbrand (2011). 2011 Ranking of the Top 100 Brands, available at: http://www.inter brand.com/de/best-global-brands/previous-years/best-global-brands-2011.aspx ～(accessed 27 January 2015).

Ishaq, M. I. (2011). A study on relationship between service quality and customer satisfaction: An empirical evidence from Pakistan telecommunication industry. Management Science Letters, 1, 523530.

Kaas, K.P. (1995). Marketing zwischen Hierarchie und Markt. In Kaas, K.P. (Ed.), Zfbf Schmalenbachs Zeitschrift für betriebswirtschaftliche Forschung, special issue, 35, 19-42.

Kang, S.-M. (2006). Measurement of acculturation, scale formats, and language competence. Journal of Cross-Cultural Psychology, 37, 669-693.

Kim, H.-S., \& Yoon, C.-H. (2004). Determinants of subscriber churn and customer loyalty in the Korean mobile telephony market. Telecommunication Policy, 31, 751-763.

Kulinna, M. (2007). Ethnomarketing in Deutschland. Frankfurt/Main: Institut für Humangeographie.

La Ferle, C., \& Lee, W.-N. (2005). Can English language media connect with ethnic audiences? Ethnic minorities' media use and representation perceptions. Journal of Advertising Research, 45, 140-153.

Laufer, D., Silvera, D.H., McBride, J.B., \& Schertzer, S.M. (2010). Communication charity success across cultures: Highlighting individual or collective achievement? European Journal of Marketing, 44, 1322-1333.

Makgosa, R. (2012). Ethnic diversity in Britain: A stimulus for multicultural marketing. Marketing Intelligence and Planning, 30, 358-378.

Michaelis, M., Dinh, H.V., Heussler, T., Meyer, M., \& Ahlert, D. (2008). Do ethnic marketing efforts pay off? Interaction effects of accomodated brand and price on product evaluation and purchase intention. Working paper, University of Münster.

OECD (2014). International Migration Outlook 2014. Paris: OECD.

Ogden, D.T., Ogden, J.R., \& Schau, H. (2004). Exploring the impact of culture and acculturation on consumer purchase decisions: Toward a microcultural perspective. Academy of Marketing Science Review, 3(1), 1-22.

Petruzzellis, L. (2010). Mobile phone choice: Technology versus marketing. The brand effect in the Italian market. European Journal of Marketing, 44, 610-634.

Polat, Ü. (2006). Soziale und kulturelle Identität türkischer Migranten der zweiten Generation in Deutschland. Hamburg: Kovač.

Rams, W. (2001). Kundenbindung im deutschen Mobilfunkmarkt. Wiesbaden: Gabler.

Richard, M. O., \& Toffoli, R. (2009). Language influence in responses to questionnaires by bilingual respondents: A test of the Whorfian hypothesis. Journal of Business Research, 62(10), 987-994. 
Rotheram, M.J., \& Phinney, J.S. (1987). Introduction: Definitions and perspectives in the study of children's ethnic socialization. In Phinney, J.S., Rotheram, M.J. (Eds.), Children's Ethnic Socialization, London: Sage, 10-28.

Ryder, A.G., Alden, L.E., \& Paulhus, D.L. (2000). Is acculturation unidimensional or bidimensional? A head-to-head comparison in the prediction of personality, self-identity, and adjustment. Journal of Personality and Social Psychology, 79, 49-65.

Sattler, H. (2006). Methoden zur Messung von Präferenzen für Innovationen. In Albers, S. (Ed.), Schmalenbachs Zeitschrift für betriebswirtschaftliche Forschung, special issue 54, 154-176.

Schlereth, C., \& Skiera, B. (2012). Measurement of consumer preferences for bucket pricing plans with different service attributes. International Journal of Research in Marketing, 29(2), 167-180.

Schneider, H., Coskun, B., \& Kelemci Schneider, G. (2010). Rollenverteilung bei Kaufentscheidungen türkischstämmiger Familien in Deutschland. Marketing ZFP, 32, 164-179.

Singh, N., Baack, D. W., Pereira, A., \& Baack, D. (2008). Culturally customizing websites for uS Hispanic online consumers. Journal of Advertising Research, 48(2), 224-234.

Statistisches Bundesamt (2014). Bevölkerung und Erwerbstätigkeit. Bevölkerung mit Migrationshintergrund, Fachserie 1 Reihe 2.2. Wiesbaden. Available on: https://www.destatis. de/DE/Publikationen/Thematisch/Bevoelkerung/MigrationIntegration/Migrationshintergrund2010 220137004.pdf?_blob=publicationFile (accessed 27 January 2015).

SyncForce (2011). Ranking the Brands Top 100, available at: http://www.rankingthebrands.co $\mathrm{m} /$ The-Brand-Rankings.aspx?rankingID=30\&year=260 (accessed 27 January 2015).

Tajfel, H., Billig, M.G., Bundy, R.P., \& Flament, C. (1971). Social categorization and intergroup baviour. European Journal of Social Psychology, 1, 149-178.

Talberg, M., Hämmäinen, H., Töyli, J., \& Kamppari, S. (2007). Impacts of handset bundling on mobile data usage: The case of Finland. Telecommunication Policy, 31, 648-659.

Trebbe, J., \& Weiß, H.-J. (2007). Integration als Mediennutzungsmotiv. Media Perspektiven, 38, 136141.

Üstüner, T., \& Holt, D.B. (2007). Dominated consumer acculturation: The social construction of poor migrants women's consumer identity projects in a Turkish squatter. Journal of Consumer Research, 34(1), 41-56.

Voeth, M., \& Hahn, C. (1998). Limit Conjoint-Analyse. Marketing ZFP, 20, 119-132.

Watchravesringkan, K. (2010). Exploring antecedents and consequences of consumer ethnocentrism: Evidence from Asian immigrants in the US. International Journal of Consumer Studies, 35, 383390.

Yağmur, K., \& Vijver, F.J. (2012). Acculturation and language orientations of Turkish immigrants in Australia, France, Germany, and the Netherlands. Journal of Cross-Cultural Psychology, 43, 11101130.

Zick, A. (2010). Psychologie der Akkulturation. Wiesbaden: VS Verlag.

Zollinger, P. (2005). Markenbewusste Mitbürger. Horizont, 22(19), 62. 


\section{Appendix}

Acculturation indicators ${ }^{\mathrm{a}}$

\section{Your country of birth?} (Please fill in)

2. What is your citizenship? (Please mark with a cross)

German (1) Turkish (0)

3. What is the country of origin of your spouse or significant other irrespective of his/her citizenship? (Please mark with a cross)
German (1)
Turkish (0)

4. What is the citizenship of your spouse or significant other? (Please mark with a cross)
German (1)
Turkish (0)

5. How many years do you already live in Germany?

$$
\text { (Please fill in) }
$$

6. How high is the share of Turks in your neighborhood? (Please mark with a cross)
High/very high (1)
Medium/low/very low (0)

7. How good are your German language skills? (Please mark with a cross)

Very good/fairly good (1)

Medium/fairly bad/very bad (0)

8. Language of the questionnaire filled in: German (1)

Turkish (0)

a) Original wording of the items was in German or Turkish and was translated into English for the present article. Bold and italic types correspond to the layout of the original questionnaire. Figures in squared brackets are the codings of the different answer categories used in Table 5. The indicator citizenship additionally offered the option "both". Questions regarding the spouse"s citizenship and country-of-origin entailed the option "other". For the indicators 6 and 7 five response options were provided. Response anchors for indicator 6 was "very low" (=1), "low" (=2), "medium“ (= 3), "high" (=4), "very high" (=5). Answer anchors for indicator 7 were "very bad“ (=1), "fairly bad“ (= 2), "medium“ (= 3), "fairly good“ (=4), "very good“ (=5). 